\title{
Crude Anthrax Protective Antigen Enhances Immunity For Salmonella Typhimurium in Mice
}

\author{
Inam J. Lafta* \\ BVM\&S , PhD (Molecular Biology) \\ Huda H. Al abbody ** BVM\&S, MSc(Internal and Preventive Veterinary Medicine)
}

\begin{abstract}
$\underline{\text { Abstract }}$
Background:Non-host-adapted Salmonella serovar Typhimurium is a facultative intracellular bacterium,

Fac Med Baghdad

2017; Vol.59, No.2

Received: Dec. 2016

Accepted: April .2017

which invades and multiplies within mononuclear phagocytes in liver, spleen, lymph nodes and Peyer's plaques. Salmonella infection is a crucial medical and veterinary problem globally. S. Typhimurium causes various clinical symptoms, from asymptomatic infection to typhoid-like syndromes in infants or highly susceptible animals, for instance mice.

Objective: The present study was carried out to investigate the efficacy of anthrax protective antigen (PA)as a potent adjuvant mixed with killed Salmonella Typhimurium (S.T.) to enhance the immunization capacity of the last.

Materials and Methods: Two groups of mice were immunized with either the mixture of S.T. and PA or S.T. alone, in addition to a control group immunized with phosphate buffered saline. Skin test and ELISA test were performed to evaluate cell-mediated and humoral immunity, respectively.

Results: The mixture group showed the best results in cell-mediated immunity.Furthermore, ELISA reading 14 days from booster dose was higher in the mixture group than S.T. alone. The mixture revealed high Ab titres compared to control or S.T. cohort 53 days from the beginning of immunization. These results were verified by histopathological examination.

Conclusions: Our findings suggest anthrax PA as a suitable and robust adjuvant for inactivated Salmonella Typhimurium vaccine in mice.
\end{abstract}

Keywords : Salmonella Typhimurium, Antrax protective antigen, killed vaccine, skin test and ELISA.

\section{Introduction:}

Non-host-adapted Salmonella serovar Typhimurium is a Gram-negative, motile, facultative intracellular bacterium, which invades and multiplies within mononuclear phagocytes in liver, spleen, lymph nodes, and Peyer's plaques (1). Salmonella infection is a crucial medical and veterinary problem globally. $S$. Typhimurium causes various clinical symptoms, from asymptomatic infection to typhoid-like syndromes in infants or highly susceptible animals, for instance mice (2) .

Emerging multi-drug-resistant Salmonella strains have rendered antibiotic treatment of the infection unsuccessful $(3 ; 4 ; 5)$. Therefore, vaccination has been paid more attention as an effective tool for the prevention of Salmonella infection (6). In the fields of medicine and veterinary medicine, there are numerous live, attenuated bacterial vaccines in use today worldwide $(7 ; 8)$. One example is the $S$. Typhimurium attenuated live vaccine whose pathogenicity can be reduced significantly by various attenuation methods. However,the attenuated live vaccine of this bacterium is still retaining its invasion capacity and thus delivers the heterologous genes into mammal cells (8).

*College of Veterinary Medicine, Zoonotic Diseases Unit, Baghdad Universityijlafta@gmail.com,

**Iraqi National Cancer Research Center, Baghdad University..
Although live vaccines usually have better protective effects when compared with inactivated vaccines (9), the humoral response, highly inducible by inactivated vaccines, is especially important for the control of faecal shedding (10). Moreover, further study on the efficacy of killed vaccines is required because of potential threats associated with the use of live attenuated Salmonella strains, such as reversion to virulence and immunosuppression (11).

The vaccines that are currently available still fail to protect against certain pathogens. One encouraging strategy for tackling this challenge is the development of new vaccine adjuvants that increase the effectiveness of vaccines. These adjuvants should have the capability to elicit a powerful immune response. The most effective immune response against multiple pathogens involves a combination of both humoral and cellular components. This is even true for some obligate intracellular pathogens. Safety is another important parameter to consider when choosing an appropriate adjuvant (12) . Concerning alum, it has been used widely and successfully in many licensed vaccines, and has a positive track record of safety. It is considered the adjuvant of choice for vaccines against infectious diseases that can be prevented by the humoral immune response. However, some limitations of alum have been described. Notably, alum is a poor inducer of cell-mediated immunity and $\mathrm{T}$ helper 1 (Th1) responses, which are both required to combat several life-threatening infections (13). 
In previous studies, it was reported that anthrax PA was able to potentiate protective immunity against a heterologous antigen (14). (15) have demonstrated that oral immunization of mice with Salmonella expressing full-length PA protected five of six mice againsta challenge with $10^{5} \mathrm{CFU}$ of aerosolized Bacillus anthracis STI spores. In a study performed by (16), crude anthrax PA was applied as an adjuvant with Brucella vaccine S19 and showed acceptable results both in cellular and humoral immunity against virulent B. melitensis. Anthrax toxin system has been used by (17) to deliver cholera toxin subunit A (CT-A) into the cytosol of mammalian cells, directing CT-A to alternative receptors of protective antigen of anthrax toxin, which are universally present on all mammalian cells. Their result suggested that anthrax lethal factor (LF)-CT-A is internalized into the cytosol through PA. Unlike many protein vaccines, the PA of $B$. anthracis has a receptor expressed by mammalian cells that may affect the type of immune response induced, as well as the presence of PA receptor (ATR) in almost all mammalian cells would augment its immunogenicity (18). Thus, there is an urgent need to develop new adjuvant formulations for use in the development of valuable vaccines against pathogens. Similar to other facultative intracellular bacteria, protection against $S$.Typhimurium requires both humoral and cellular immunity (13).

For those reasons, in the present study we investigated the use of crude anthrax PA with killed $S$. Typhimurium vaccine in order to improve its efficacy in immunizing mice against challenge with virulent $S$. Typhimurium.

\section{Materials and Methods}

Bacteria. Salmonella Typhimurium and Bacillus anthracis Sterne strain (34F2) were used in this study. Bacillus anthracis Sterne strain (34F2) is a nonvirulent strain that contains PXO1 plasmid, which controls the production of anthrax toxins, but naturally lost its $\mathrm{PXO} 2$ plasmid, which codes for the capsule. Both bacteria were obtained from Zoonotic Diseases Unit, Veterinary Medicine College/Baghdad University, Baghdad, Iraq. Their morphological and biochemical characteristics were verified according to the method of (19).

Adjutants. Anthrax PA was prepared according to the method of (20) modified by (16).

Bacterial suspension. It was prepared by growing the purified bacteria on blood agar plates for $24 \mathrm{~h}$, and then harvesting the bacterial growth by sterile glass rod with neutral phosphate buffered saline (PBS). The PBS solution was made by dissolving $8 \mathrm{~g} \mathrm{NaCl}, 1.15 \mathrm{~g}$ $\mathrm{Na}_{2} \mathrm{HPO} 4, \mathrm{KH}_{2} \mathrm{PO} 4$ and $\mathrm{KCl}$ each $0.2 \mathrm{~g}$ into $1 \mathrm{~L}$ distalled water. Following autoclaving at $121^{\circ} \mathrm{C}$ and 15 psi for $15 \mathrm{~min}$, the $\mathrm{pH}$ was adjusted to 7.4 by adding drops of $\mathrm{HCl}$ or $\mathrm{NaOH}$ (21). The bacterial number in the suspension was calculated according to the method of (22)and compared with McFarland tubes.

To make bacterial suspension, the bacteria was streaked on a tryptone soy agar and incubated at $37^{\circ} \mathrm{C}$ overnight. Five well-isolated colonies were selected by loop, and transferred to a tube containing tryptone soy broth. Then, bacterial suspension containing approximately $1 \times 10^{8}$ bacteria per $\mathrm{ml}$ was made by comparing its turbidity to a $0.5 \mathrm{McFarland}$ turbidity standard.Afterwards, 10-fold serial dilutions were made from the suspension in seven sterile tubes, each containing $4.5 \mathrm{ml}$ tryptone soy broth. After labelling the tubes from 1 to $7,0.5 \mathrm{ml}$ of bacterial suspension (equivalent to $0.5 \mathrm{McFarland}$ standard) was added to the tube number 7 and mixed vigorously. Then, $0.5 \mathrm{ml}$ was withdrawn from tube 7 to tube 6 and also mixed well. This process continued till tube 1 using the same insulin syringe connected to needle used to transfer and mix the bacterial suspension throughout different tubes. Using the same syringe, $0.1 \mathrm{ml}$ suspension was transferred from tube 1 to a plate labeled 1. Similarly, the process of transferring $0.1 \mathrm{ml}$ from tube 2 to plate 2 , and tube 3 to plate 3 , continued by using the same syringe. The process above was repeated till tube 7 . Using a bent rod, the bacterial fluid was spread over the entire surface of each plate. The inoculated plates were incubated overnight, and the number of colonies on each plate was counted manually especially for plates containing no more than 300 colonies per plate. By adding $0.5 \mathrm{ml}$ of the original bacterial suspension to the $4.5 \mathrm{ml}$ of broth in tube 7 , the tube contains approximately $10^{7}$ bacteria per $\mathrm{ml}$. Later, $0.1 \mathrm{ml}$ of this suspension was transferred to plate 7 , which contains now approximately $10^{6}$ bacteria. Approximately $10^{5}$ bacteria should be present on the plate number 6 .

Laboratory animals.Twenty three Swiss albino white mice from hothgenders, 6 week aged and 20-25 gm weighted were purchased from Veterinary Medicine College. Mice were divided as following:-

Two mice were used to collect blood and culture all the internal organs to confirm the lack of mice used in this experiment from any microbial infections and absence of anti $S$. Typhimurium antibodies.

Six mice were used to calculate minimum lethal dose, as follows:

One mouse was injected with $S$. Typhimurium suspension containing $1 \times 10^{6} \mathrm{CFU} / \mathrm{ml}$ in a dose of $0.2 \mathrm{ml} \mathrm{s} / \mathrm{c}$.

A mouse was injected like above but the suspension contained $1 \times 10^{7} \mathrm{CFU} / \mathrm{ml}$.

A mouse was injected with $3 \times 10^{8} \mathrm{CFU} / \mathrm{ml}$ suspension in a dose of $0.25 \mathrm{ml} \mathrm{s} / \mathrm{c}$.

A mouse was inoculated s/c with $0.25 \mathrm{ml}$ of suspension contained $6 \times 10^{8} \mathrm{CFU} / \mathrm{ml}$.

A mouse was inoculated as above (suspension contained $6 \times 10^{8} \mathrm{CFU} / \mathrm{ml} \mathrm{s} / \mathrm{c}$ ), but in a dose of $0.3 \mathrm{ml}$.

The last one was injected $\mathrm{s} / \mathrm{c}$ with a suspension of $6 \times 10^{8} \mathrm{CFU} / \mathrm{ml}$ in a dose of $0.5 \mathrm{ml}$. 
Fifteenmice were divided equally into three groups and used for immunization of the following groups s/c with $0.1 \mathrm{ml}$ as bellow:-

Group 1: mixture of S.T. and PA.

Group 2: S.T. only.

Group 3: control, immunized with PBS.

After 14 days, all groups of mice were given the second dose as the first immunization.

Preparation of Salmonella antigen used for skin test: Salmonella antigen was prepared according to the method of (23) with some modifications, as below:

1- Prepare $S$. Typhimurium suspension containing $6 \times 10^{8} \mathrm{CFU} / \mathrm{ml}$ as mentioned previously.

2- Culture $250 \mathrm{ml}$ nutrient broth with $2 \mathrm{ml}$ of the above suspension at $37^{\circ} \mathrm{C}$ for $24 \mathrm{~h}$.

3- Purification detection was done by observing culture characteristics, in addition to staining with Gram's stain.

4- Put the cultured media in $50 \mathrm{ml}$ centrifuge tubes for centrifugation at 4000 RPM for $30 \mathrm{~min}$, and then wash the sediment twice at the same speed for $15 \mathrm{~min}$.

5- Add suitable amount of PBS to the sediment (pellet) and compare with McFarland tube no. 2 that contains $6 \times 10^{8} \mathrm{CFU} / \mathrm{ml}$.

6- Put the suspension in autoclave at $121{ }^{\circ} \mathrm{C}$ for 30 min.

7- Keep in refrigerator until use.

KilledS.Typhimurium (S.T.) vaccine. The vaccine of $S$.Typhimurium was prepared following the method of OIE (24), with some modifications.

It was prepared as above (the steps 1-4 were the same). 5- After centrifugation, PBS containing $0.4 \%$ formalin was added to the pellet and incubated at $37^{\circ} \mathrm{C}$.

6- Culture on blood agar plate was done once daily to confirm killing of bacteria.

7- After bacterial killing, it was washed 3 times with PBS by centrifuge at 3000 RPM for $15 \mathrm{~min}$.

8- The sediment was suspended with PBS to become equal to McFarland tube no. $2\left(6 \times 10^{8} \mathrm{CFU} / \mathrm{ml}\right)$, and it was denoted as S.T. in this study.

9- Killed vaccine (S.T.) was mixed in a proportion of 1:1 with anthrax PA, and was denoted as mixture in this study.

Skin test. Skin test or Delayed-type hypersensitivitytest (DTH) was performed 32 days from the beginning of immunization i.e. the skin test was applied in the day 18 from the second immunization dose, in which the right foot pad of each mouse was injected I.D. with $0.1 \mathrm{ml}$ Salmonella antigen using disposable insulin syringe and sterile PBS to the left foot pad in the same way as a control. Skin thickness was read before injection, 24 and $48 \mathrm{~h}$ post-injection using caliper. After 35 days of immunization, 2 mice from each group were anesthetized with inhaled ether, and then were sacrificed. Blood was collected directly from heart without anticoagulant to obtain serum for ELISA.
Pieces of organs about $1 \mathrm{~cm}^{3}$ thickness from spleen and liver were kept in 10\% Neutral Buffered Formalin for studying histological changes (25).

Protection experiment. Protection experiment was performed according to the method of (26) with some modifications. Mice in all groups were challenged 53 days post-immunization by $\mathrm{s} / \mathrm{c}$ injection of $6 \times 10^{8}$ $\mathrm{CFU} / \mathrm{ml} S$. Typhimurium in a dose of $0.25 \mathrm{ml}$. After 10 days of challenge, all mice were anesthetized with ether and sacrificed to collect blood for ELISA. Few drops of blood and pieces of internal organs (lung, kidney, liver, and spleen) were used for bacterial culturing on blood agar and MacConkeys agar. Parts of spleen and liver were used for histopathological examination as described previously.

Enzyme Linked Immunosorbent assay (ELISA).Antibody titers were estimated using ELISA kit (SYNBIOTICS, French), according to the instructions of the manufacturer. Blood was collected from mice after 35 and 53 days of immunization using suitable tubes without anticoagulant. Blood was put for $30 \mathrm{~min}$ in refrigerator, and then centrifuged at 3000 RPM for 10 min to obtain serum for ELISA. ELISA reader was used to record the results as optical density (OD) for each serum sample on the wave length 450 nanometer. The value 0.153 and above was regarded positive, while the reading below 0.153 was considered as negative, according to the manufacturer's recommendations.

\section{Results:}

Determination of challenge dose (minimum lethal dose): Mice injected with $S$. Typhimurium suspension containing $1 \times 10^{6} \mathrm{CFU} / \mathrm{ml}$ in a dose of $0.2 \mathrm{ml}, 1 \times 10^{7}$ $\mathrm{CFU} / \mathrm{ml}$ in the same dose and $3 \times 10^{8} \mathrm{CFU} / \mathrm{ml}$ in a dose of $0.25 \mathrm{ml}$, separately were not affected. Mice injected with $0.3 \mathrm{ml}$ and $0.5 \mathrm{ml}$ suspension containing $6 \times 10^{8} \mathrm{CFU} / \mathrm{ml}$ succumbed after $48 \mathrm{~h}$ and $24 \mathrm{~h}$, respectively. While the mouse injected with $0.25 \mathrm{ml}$ of $6 \times 10^{8} \mathrm{CFU} / \mathrm{ml}$ suspension succumbed after $72 \mathrm{~h}$ and this dose was regarded as the minimal lethal dose used in the experiment. DTH. High difference of skin thickness was noticed in the group vaccinated with the mixture (PA and S.T.) with the mean $1.46 \pm 0.50 \mathrm{~mm}$ after $24 \mathrm{~h}$ and $1.42 \pm 0.55 \mathrm{~mm}$ after $48 \mathrm{~h}$. The group immunized with S.T. only showed the least difference of skin thickness of $0.76 \pm 0.30 \mathrm{~mm}$ after $24 \mathrm{~h}$ and 0.81 $\pm 0.55 \mathrm{~mm}$ after $48 \mathrm{~h}$ (Figure 1). 


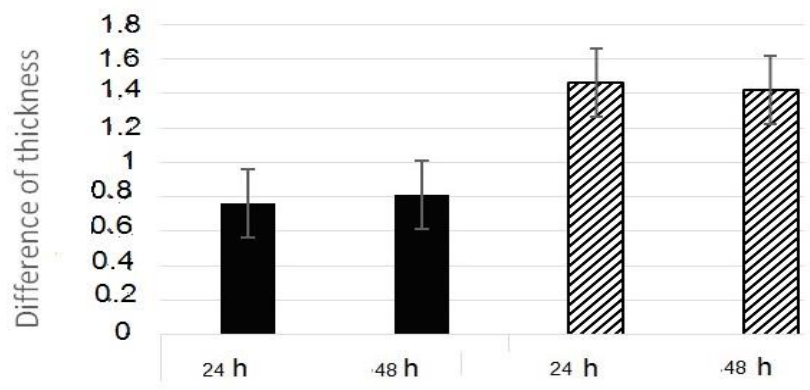

Figure (1) Higher Difference of Thickness in Foot Pad of Mice Immunized with (S.T. and PA).

Mice wereimmunized with either the mixture (S.T. \& PA) or S.T. alone. Skin test test was performed 18 days from the second immunization dose.The right foot pad of each mouse was injected I.D. with $0.1 \mathrm{ml}$ Salmonella antigen and sterile PBS to the left foot pad as a negative control. Skin thickness was read before injection, 24 and $48 \mathrm{~h}$ post-injection.

ELISA. After 35 days of immunization; 14 days from booster dose, the results were $0.635 \pm 0.059 \mathrm{~nm}$ for S.T. only without adjuvant and $0.972 \pm 0.241 \mathrm{~nm}$ for the mixture of S.T. and PA.Fifty three days from the beginning of immunization, the mixture showed the highest $\mathrm{Ab}$ titers of $1.866 \pm 0.011 \mathrm{~nm}$ compared to $0.535 \pm 0.256$ for S.T. group.

Table 1 Shows ELISA Reading Following Immunization with S.T. only or Mixture.

\begin{tabular}{lll}
\hline Group & 14 days post booster & 53 days post immunization \\
\hline S.T. only & $0.635 \pm 0.059 \mathrm{~nm}$ & $0.535 \pm 0.256 \mathrm{~nm}$ \\
\hline Mixture & $0.972 \pm 0.241 \mathrm{~nm}$ & $1.866 \pm 0.011 \mathrm{~nm}$ \\
\hline
\end{tabular}

Protection experiment. In immunized animals, no important macroscopic lesions were noticed on different organs, but only enlargement of spleen in mice vaccinated with the mixture.Mice immunized with S.T. only do not show any lesion. There were no bacteria isolated from internal organs cultured on bacteriological media.In control animals,macroscopic changes in mice challenged with $S$. Typhimurium

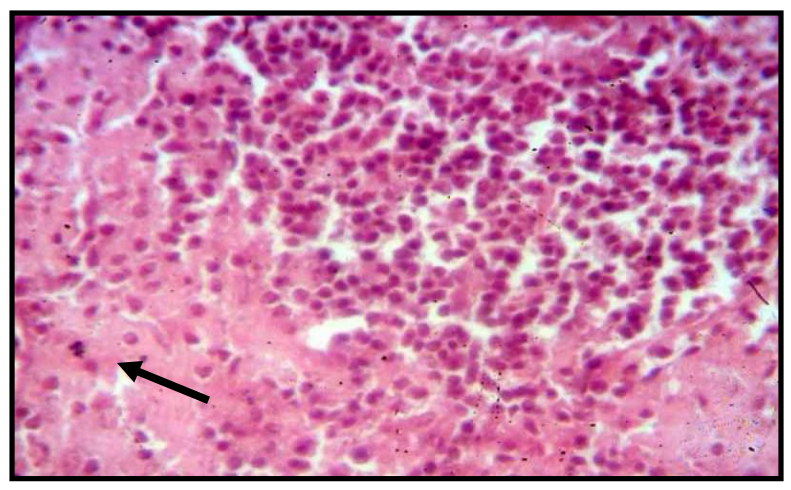

Figure (2) Histological Section in Liver of an Animal Immunized with the Mixture. involved enlargement and paleness of liver with slight enlargement of spleen and petechial hemorrhage on lung surface.

After challenge of control animals with $0.5 \mathrm{ml}$ of $6 \times 10^{8} \mathrm{CFU} / \mathrm{ml} S$. Typhimurium, bacteria were isolated from mice in large numbers $(++++)$ from spleen. There were no bacteria isolated from heart, lung, and kidney after $24 \mathrm{~h}$ of animal death. Animals challenged with $0.25 \mathrm{ml}$ of $6 \times 10^{8} \mathrm{CFU} / \mathrm{ml} S$. Typhimurium were succumbed to death after $72 \mathrm{~h}$ of injection, bacteria were isolated in large numbers $(++++)$ from spleen, $(+++)$ from blood, $(++)$ from liver and few numbers $(+)$ from kidney.The symbol + refers to the intensity of bacterial numbers, where ++++ indicates severe infection than the symbol + .

Pathological changes. In group one, where mice were immunized with (S.T. and PA), the histopathological changes in liver 14 days post-immunization involved moderate mononuclear cell aggregation around the central vein with proliferation of kupffer cells (Figure 1). In spleen, there was moderate hyperplasia of white pulp.

In group two, where mice were immunized with S.T. only, the histopathological changes in spleen after 14 days of immunization revealed moderate hyperplasia of white pulb and moderate mononuclear cells aggregation around the sinusoid (Figure 2).Histological changes in liver ten days after challenge showed proliferation of kupffer cells with moderate mononuclear cells infiltration in liver parenchyma. Spleen showed moderate white pulb hyperplasia with proliferation of megakaryocytes, while in another animal, there was proliferation of mononuclear cells around the sinusoid.

Control group immunized with PBS and challenged, revealed severe changes in liver included multiple area of necrosis in liver parenchyma with inflammatory cells infiltration and dilatation of sinusoid (Figure 3). Spleen in the main lesion characterized by depletion of white pulb with inflammatory cells infiltration in the red pulb. Additionally, spleen of other animals showed amyloid- like substance deposition around the depleted white pulb.

Histological section in liver of an animal immunized with (S.T. and PA mixture) 14 days postimmunization shows marked lymphocytic cell aggregation around the blood vessels and in liver parenchyma (H and E 40x). 


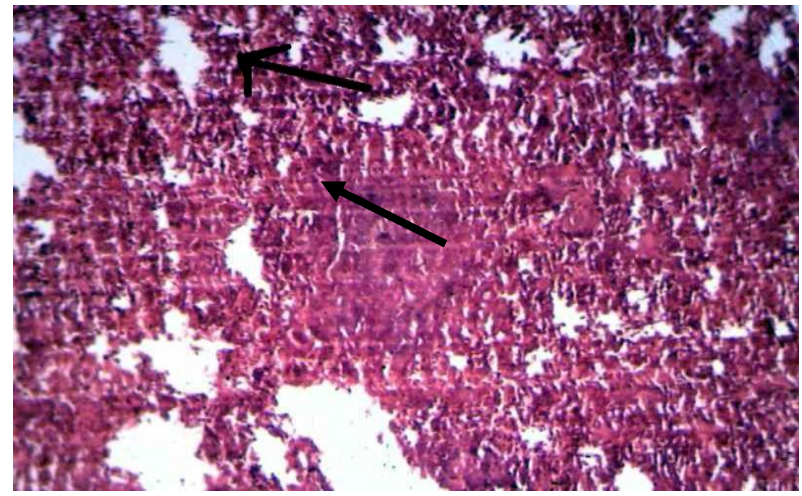

Figure (3) Histological Section of Spleen of an Animal Immunized with S.T. alone.

Histological section of spleen of an animal immunized with S.T. alone and challenged with virulent $S$. Typhimurium shows moderate hyperplasia of white pulband moderate proliferation of mononuclear cells around the sinus (H and E 40x).

Figure (4)Histological Section in Liver of one Control Infected Animal.

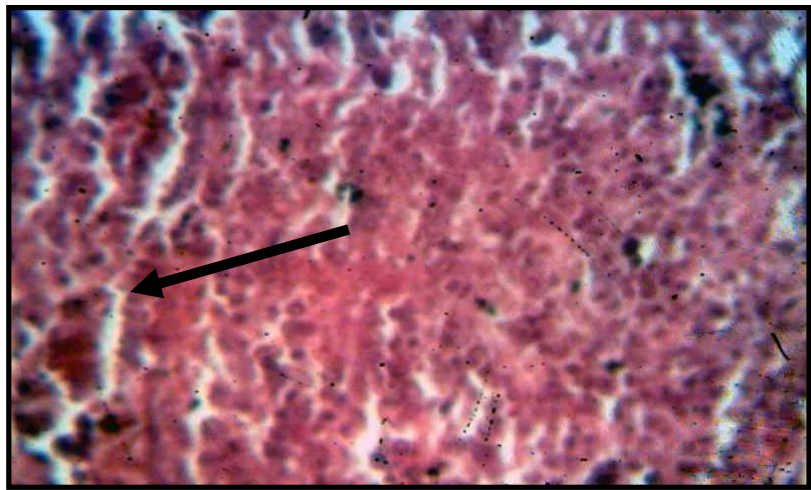

Histological section in liver of one control animal infected with virulent $S$. Typhimurium shows congestion of central vein and sinusoid with inflammatory cells (macrophage and neutrophil) infiltration in the interstitial ( $\mathrm{H}$ and $\mathrm{E} \mathrm{40x}$ ).

\section{Discussion}

There are currently several licensed vaccines for Salmonella enterica serovar Typhi, but these vaccines are generally ineffective against other Salmonella serovars $(27 ; 28)$.Vaccines that affect paratyphoid and nontyphoidal Salmonella serovars are also very much in need (28).Although killed vaccines are not very effective, theyare still the best for use where the disease is eradicated and are the preferred choice for eradication of an endemic strain from a herd or when handling salmonellosis outbreak (13). Killed vaccines have not been regarded to be as effective as live attenuated vaccines in provoking protective immunity to Salmonella. While killed vaccines produce an accepted level of antibody production, they are poor inducers of cell mediated immunity $(11 ; 13)$. Moreover, it has been found that the high level of IL-1, IL-6, and IL-8 and nitric oxide production representinghost inflammatory and pro-inflammatory responses increased by the killed vaccine (11).Therefore, the present study has concentrated on the use of killed $S$. Typhimurium vaccine mixed with an adjuvant. We suggest that anthrax protective antigen is able to potentiate a humoral response against heterologous antigens, as have seen in this study, the mixture S.T. and $\mathrm{PA}$ gave high $\mathrm{Ab}$ titres in ELISA after immunization. Crude PA of anthrax toxin used in the current study may contain some amounts of the other toxin components such as lethal factor(LF). (14) have declared that PA binds to ubiquitous receptor on the surface of mammalian cells and is cleaved by furinlike proteases. This processing results in the release of $20 \mathrm{kDa}$ amino-terminal fragment, and the cellassociated $63 \mathrm{kDa}$ fragment interacts with LF. The PA63-LF complex is then internalized by receptormediated endocytosis. LF is translocated into the cytosol. The amino-terminal part of LF binds to PA63. Fusion proteins consisting of LF and heterologous antigens have been shown to be successfully delivered to cells via PA (14). In our study, mice immunized with S.T. and PA mixture revealed higher cellular immunity (DTH) relative to control or animals immunized with S.T. alone. These findings verify that PA induces not only humoral immunity but also cellmediated immunity and these results are consistentwith(16).It has been observed that using a vehicle containing nontoxic components of the anthrax toxin i.e. PA and associative domain of the LF could activate cytotoxic T-lymphocyte (29).

In this study, killed S.T. vaccine without adjuvant showedlower results in humoral and cellular immunity.Elevated humoral response to the inactivated vaccines is not only associated with the viablility status of the vaccine but also with the route of vaccine application and the presence of adjuvants in the inactivated vaccines (30).We noticed that the mixturegroup elicitedimproved immunity, which was confirmed viathe histological test.This immunity is characterized by mononuclear cells infiltration in both liver and spleen. Histopathological lesions, on the other hand, were severe in control animals challenged with virulent $S$. Typhimurium.Systemic infection of mice with $S$. Typhimurium results in rapid uptake of these bacteria by mononuclear phagocytes in liver and spleen and Salmonella - specific Abs enhance this uptake (31). Intracellular bacteria would not undergo lysis in the lysosomes immediately but survive for a period of time. They could provide a reservoir of antigen (32). In liver and spleen, $S$. Typhimurium survives within mononuclear phagocytes (33) where bacteria are shielded from Abs. As a consequence, mechanisms that activate macrophages are necessary to control $S$. Typhimurium. The importance of macrophage activation is emphasized by the high susceptibility to $S$. Typhimurium of mice deficient in IFN- $\gamma$ receptor or of mice in which IFN- $\gamma$ or TNF- $\alpha$ are neutralized with specific Abs (34). Both IFN- $\gamma$ and TNF- $\alpha$ are crucial for macrophage activation. T cells 
are involved in this process either by secreting macrophage-activating cytokines such as IFN- $\gamma$ or by direct $\mathrm{T}$ cell-macrophage interactions. An important function of CD4+ T cells is to provide help for the activation and differentiation of B cells (35).

We suggest studying the mechanism of action of adjuvant particularly crude PA and see whether it contains other traces of oedema and/or lethal anthrax toxin components. Might be try examining the mixture (PA and S.T.) for immunizing a larger group of laboratory animals other than mice followed by infecting with other Salmonella serovars or the same one used in this study. In our study, anthraxPA showed prominent protection in mice against virulent $S$. Typhimurium compared to the results of using the killed vaccine alone without adjuvant.To our knowledge, this study is the first in which crude anthrax PA was mixed with inactivated $S$. Typhimurium vaccine to enhancethe immunity against virulent $S$. Typhimurium.

Author contributions:

Inam J. Lafta: This study was conceived and designed , data analysis and interpretation manuscript.

Huda H. Al abbody: manuscript

\section{Acknowledgments:}

The authors strongly appreciate the College of Veterinary Medicine, particularly Zoonotic Diseases Unite, Baghdad University, Baghdad, Iraq for providing the research requirements. Furthermore, the authorsare thankful to the farm of the aforementioned college for dealing with the laboratory animals.

\section{References}

1- Richter-Dahlfors A, Buchan AM, Finlay BB (1997). Murine salmonellosis studied by confocal microscopy: Salmonella typhimurium resides intracellularly inside macrophages and exerts a cytotoxic effect on phagocytes in vivo. J. Exp. Med. 186(4):569-80.

2- Todar K (2005). Salmonella and salmonellosis. Toder's Online Textbook of Bacteriology.

3- Bacon RT, Ransom JR, Sofos JN, Kendall PA, Belk $K E$ and Smith GC (2003). Thermal inactivation of susceptible and multiantimicrobial-resistant Salmonella strains grown in the absence or presence of glucose. Appl. Enviro.Microbiol. 69(7): 4123-4128.

4- Begum F, Adachi $Y$ and Khan MSR (2008). Immunological characterization of $37.81 \mathrm{kDa}$ common immunodominant surface protein of some Salmonella serovars. Bangl. J. Vet. Med. 6(2): 145-151.

5- Shahada F,Sekizuka T,Kuroda M,Kusumoto M,Ohishi D,Matsumoto A,Okazaki H,Tanaka K,Uchida I,Izumiya H, Watanabe H,Tamamura Y,Iwata Tand AkibaM (2011). Characterization of Salmonella entericaSerovar Typhimurium isolates harboring a chromosomally encoded CMY-2 $\beta$-lactamase gene located on a multidrug resistance genomic island. Antimicrobial agents and chemotherapy. 55(9): 41144121.

6- Mastroeni P and Menager N (2003). Development of acquired immunity to Salmonella. J. Med.Microbiol. 52: 453-459.

7- Saxena M, Hao Van TT, Baird FJ,Coloe PJand Smooker PM (2013). Pre-existing immunity against vaccine vectors - friend or foe? Microbiology. 159: 111.

8- Jazayeri SD,Ideris A,Zakaria Zand Omar AR (2012). Attenuated Salmonellatyphimurium SV4089 as a potential carrier of oral DNA vaccine in chickens.J. Biomedicine and Biotechnol.2012: 1-8.

9- Robertsson JA, Lindberg AA, Hoiseth S and Stocker $B A$ (1983): Salmonella typhimurium infection in calves: protection and survival of virulent challenge bacteria after immunization with live or inactivated vaccines. Infect.Immu. 41:742-750.

10- Desmidt M, Ducatelle R, Mast J, Goddeeris BM, Kaspers $B$ and Haesebrouck F (1998): Role of the humoral immune system in Salmonella enteritidisphage type four infection in chickens. Vet.Immuno. Immunopathol. 63: 355-367.

11- Okamura M, Lillehoj HS, Raybourne RB, Babu US and Heckert RA (2004). Cell-mediated immune responses to a killed Salmonella enteritidis vaccine: lymphocyte proliferation, T-cell changes and interleukin-6 (IL-6), IL-1, IL-2, and IFN- $\gamma$ production. Comparative Immunol. Microbiol. \& Infect. Dis. 27: 255-272.

12- Jazani NH, Sohrabpour M, Mazloomi E and Shahabi $S$ (2011). Anovel adjuvant, a mixture of alum and the general opioid antagonist naloxone, elicits both humoral and cellular immune responses for heatkilledSalmonella typhimurium vaccine. FEMS Immunol. Med.Microbiol. 61: 54-62.

13- Singh BR (2009). Salmonella vaccines for animals and birds and their future perspective. The Open Vaccine Journal. 2: 100-112.

14-Brossier F, Weber-Levy M, Mock $M$ and Sirard J$C$ (2000). Protective antigen- mediated antibody response against a heterologous protein produced in vivo by Bacillus anthracis. Infect Immun. 68(10): 5731-5734.

15- Stokes MGM, Titball RW, Neeson BN, Galen JE, Walker NJ, Stagg AJ, Jenner DC, Thwaite JE, Nataro JP, Baillie LWJ and Atkins HS (2007). Oral administration of a Salmonella enterica-based vaccine expressing Bacillus anthracis protective antigen confers protection against aerosolized $B$. anthracis.Infect.Immuni. 75(4): 1827-1834.

16- Lafta I J (2012). Evaluation of crude anthrax protective antigen as an adjuvant for Brucella abortus vaccine in mice. Eng. and Tech. Journal. 30 (3): 500511.

17- Sharma M, Khanna H, Arora $N$ and Singh $Y$ (2000). Anthrax toxin-mediated delivery of cholera 
toxin-A subunit into the cytosol of mammalian cells. Biotechnol. Appl. Biochem. 32: 69- 72.

18- Boyaka PN, Tafaro A, Fischer R, Leppla SH, Fujihashi K and McGhee JR (2003). Effective mucosal immunity to anthrax: neutralizing antibodies and Th cell responses following nasal immunization with protective antigen. J.Immunol. 170: 5636-5643.

19- Winn WC, Allen SD, Janda WM, Koneman EW, Procop GW, Schreckenberger PC and Woods GL (2006). Koneman's Color Atlas and Textbook of Diagnostic Microbiology. $6^{\text {th }}$ ed. Lippincott William's and Wilkins Company, Philadelphia.

20- Haines BW, Klein F and Lincoln RE (1965). Quantitative assay for crude anthrax toxins. $J$ Bacteriol. 89(1): 74- 83.

21- Hudson L and Hay FC (1980). Practical Immunology. $2^{\text {nd }}$ ed. Black well Scientific Publications, Oxford. Pp: $328-340$.

22- Harley JP and Prescott LM (2002). Determination of bacterial numbers. In: Laboratory Exercises in Microbiology. $5^{\text {th }}$ ed. The McGraw-Hill Companies. Pp: 117-120.

23- Mukkur TKS, McDowell GH, Stocker BAD and Lascelles AK (1987). Protection against experimental salmonellosis in mice and sheep by immunisation with aromatic-dependent Salmonella typhimurium. J. Med. Microbiol. 24(1): 11-19.

24- OIE (Office International Des Epizooties) (2004). Salmonellosis and fowl typhoid and pullorum diseases. In: OIE Guide- 2. Manual of Diagnostic tests and vaccines for terrestrial animals.

25- Luna LG (1968). Manual of histologic staining methods of the armed forces institute of pathology. $3^{\text {rd }}$ ed. Mc graw-Hill, New York.

26- Kenny K and M Herzberg (1967). Early antibody response in mice to either infection or immunization with Salmonella typhimurium. J. Bacteriol. 93(3): 773778.

27- Tennant SM and Levine MM (2015). Live attenuated vaccines for invasive Salmonella infections. Vaccine 33(Suppl 3):C36-C41.

28- Higginson EE, SimonR and Tennant SM (2016). Animal Models for Salmonellosis: Applications in Vaccine Research. Clinical and Vaccine Immunology. 23 (9): 746-756.

29- Kravchenko TB, Titareva GM, Bahteeva IV, Noskova RI, and Noskov AN (2001). Nontoxic anthrax toxin component is a unique delivery system for protein presentation. $4^{\text {th }}$ International Conference on Anthrax, June 10-13. St. Johns College, Annapolis, Maryland, USA.

30- Papezova K, Havlickova H, Sisak F, Kummer V, Faldyna $M$ and Rychlik I (2008). Comparison of live and inactivated Salmonella Typhimurium vaccines containing different combinations of SPI-1 and SPI-2 antigens in poultry. Vet. Med. 53(6): 315-323.

31- Saxen $H$ (1984). Mechanism of the protective action of anti-Salmonella IgM in experimental mouse salmonellosis. J Gen.Microbiol. 130:2277.
32- Meng FP, Ding J, Yu ZC, Han QL, Guo CC, Liu N and Fan DM(2005). Oral attenuated Salmonella typhimurium vaccine against MG7-Ag mimotope of gastric cancer. World J.Gastroenterol. 11(12): 18331836.

33- Richterdahlfors A, Buchan AM J and Finlay BB (1997). Marine salmonellosis studied by confocal microscopy: Salmonella typhimurium resides intracellularly inside macrophages and exerts a cytotoxic effect on phagocytes in vivo. J. Exp. Med. 186:569.

34- Nauciel $C$ and Espinasse-Maes F (1992). Role of gamma interferon and tumor necrosis factor $\alpha$ in resistance to Salmonella typhimurium. Infect. Immun. 60:450.

35- Mittrucker HW, Raupach B, KohlerA and Kaufmann SHE (2000). Role of B lymphocytes in protective immunity against Salmonella typhimurium infection. J. Immunol.164: 1648-1652. 